\title{
SOBRE EL ESTADO. CURSOS EN EL COLLÈGE DE FRANCE (1989-1992),
}

por PIERRE Bourdieu. Barcelona: Anagrama, 2014, 577 páginas. ISBN: 97884-339-6369-7

\section{GÉNESIS DEL LEVIATÁN: CAMPO DE TODOS LOS CAMPOS Y BANCO CENTRAL DE LA DOMINACIÓN SIMBÓLICA}

\section{Dos apuestas estratégicas: violencia simbólica y teoría de los campos}

Viene pintiparada a la tarea que nos ocupa evocar que «una obra no es accesible en su totalidad sino como póstuma». ${ }^{1}$ En efecto, inéditos y póstumos estos tres cursos (1989-1991) pronunciados en el Collège de France, sancta sanctorum del campo académico francés, contribuyen a conocer mejor, engrandecer y dar nuevo brillo a la figura de Pierre Bourdieu, uno de los sociólogos más citados, traducidos y universalmente reconocidos del siglo XX. Su obra, de dimensiones oceánicas y afanes proteicos, ha sido calificada de «constructivismo estructuralista» o «estructuralismo genético», sintagmas bajo los que se persigue acoger una mirada teórica que, sin renunciar al peso causal de las conexiones profundas existentes entre el mundo estructural y la acción subjetiva, reclama la dimensión histórica (genética) e inventada (constructiva) de las relaciones entre ese mundo y esas acciones. En el caso que nos concierne, el objeto de su trabajo es el Estado, institución que, como reconocen los mismos editores de estos cursos, fue motivo de atención un tanto tardía. En efecto, sólo desde principios de los ochenta, cuando su quehacer era ya muy sobresaliente, comparece, especialmente en dos de sus títulos más conocidos, Homo academicus (1984) y La noblesse d'État: grandes écoles et esprit de corps (1989), la centralidad del Estado como instancia monopolizadora de la violencia simbólica legítima. ${ }^{2}$

\footnotetext{
${ }^{1}$ Pierre Bourdieu, Capital cultural, escuela y espacio social (México, Siglo XXI, 2005), 20.

2 Ambas obras editadas por Minuit, en cuya colección «Le sens común», dirigida por él mismo, se publicaron parte muy sustancial de sus pesquisas hasta 1992, las de sus discípulos y otros distinguidos sociólogos. La versión española de estos dos libros corrió a cargo de Siglo XXI (Buenos Aires, 2008 y 2013,
} 
En cierto modo, se diría que su creciente interés por la institución estatal se vincula al progresivo desarrollo, matización y aplicación de dos de sus hallazgos heurísticos más poderosos, a saber, el de la violencia simbólica y la teoría de los campos.

En cuanto al primero, la elaboración de violencia simbólica como herramienta heurística se relaciona con su radical voluntad de romper con el economicismo sociológico, otorgando a la dimensión cultural un papel decisivo y autónomo en los procesos de constitución y reproducción de las instituciones sociales. En efecto, desde los años sesenta, primero en el seno del Centro de Sociología Europea y luego en el Centro de Sociología de la Educación y la Cultura, venía explorando las formas en que ocurría la transmisión de los recursos simbólicos en la vida social. Fruto de ese interés, en 1970 vio la luz el ya clásico, La reproduction. Éléments pour une théorie du système d'enseignement, donde más allá de las críticas tan habituales hoy de funcionalismo al revés y de «reproduccionismo», el concepto de «violencia simbólica» empieza a ocupar el punto neurálgico de su universo sociológico. ${ }^{3}$ En efecto, siguiendo la estela weberiana sobre las formas de

respectivamente), editorial que al lado de Taurus, Anagrama, etc. han facilitado el acceso de una buena parte de su producción (desde sus trabajos principales hasta multitud de antologías o sueltos de artículos, entrevistas e intervenciones públicas) a los lectores hispanohablantes. Desde luego, pocos ejemplos existen de una difusión tan universal de un quehacer muy representativo del espacio intelectual cuajado en el proceso de globalización. El propio Bourdieu cuidó con mimo sus muchas empresas intelectuales y la relación de sus obras con determinadas editoriales. En 1996, seis años antes de su muerte, fundó Raisons d'agir (plataforma de intervención y editorial) y antes, en 1975, impulsó y dirigió la revista Actes de la recherche en sciencies sociales, verdadero surtidor de indagaciones que siguen su senda teórica. En todo caso, hoy su producción científica y las interpretaciones de la misma navegan en internet quebrando las limitaciones de la cultura escrita en papel. Perteneciente a la última generación de los maîtres à penser, es también un intelectual-puente entre los usos de la cultura escrita tradicional y la cultura escrita electrónica propia de la era del capitalismo cognitivo.

${ }^{3}$ La reproduction..., escrito por P. Bourdieu y J. C. Passeron, se publicó en Minuit (Paris, 1970), y tuvo la primera versión española como La reproducción. Elementos para una teoría del sistema de enseñanza (Barcelona: Laia, 1977). Por cierto, el propio Bourdieu, mucho después, siguió defendiendo esa obra seminal: «Es un libro que describe las cosas como son, un libro que es confirmado por la observación. Veinte años después veo que es aún más verdadero de lo que yo creía» (P. Bourdieu, Capital cultural, escuela y espacio social, México: Siglo XXI), 157, pero también era plenamente consciente de que el libro contenía «un pensamiento que hiere y además es difícil» (Ibíd., p. 159). Sin embargo, hay quienes ven una discontinuidad entre ese Bourdieu «reproduccionista» y el de su obra de madurez. Según tal punto de vista, en el primero habría una proclividad funcionalista (en los primeros usos de «violencia simbólica» $\mathrm{y}$ «habitus»), que evolucionaría hacia una perspectiva más rica cuando sus análisis de la educación se inscriben en su teoría de los campos. Véase al respecto, Enrique Martín Criado, «De la reproducción al campo escolar», en L. E. Alonso, Enrique Martín Criado y José Luis Moreno Pestaña (eds.), Pierre Bourdieu, las herramientas del sociólogo (Madrid: Fundamentos, 2004), 66-114. Resulta muy útil y esclarecedora la posición de Jean Claude Passeron en «Hegel o el pasajero clandestino. La reproducción social y la historia», en El razonamiento sociológico (Madrid, Siglo XXI), 181-202. Véase también del mismo 
dominación, define la «violencia simbólica» como la capacidad de imponer significaciones (ideas de carácter universal) como legítimas ocultando las relaciones de fuerza (de poder) que tras ellas se amparan. Es así como llega a la celebérrima definición de la acción pedagógica como «violencia simbólica» en tanto que imposición, por un poder arbitrario, de una arbitrariedad cultural. ${ }^{4}$ La misma huella weberiana reaparecerá desde el principio del libro que comentamos, cuando Bourdieu defina al Estado como «monopolio de la violencia física y simbólica legítimas» (p. 14), enmendando la plana parcial y sutilmente a Weber para quien la exclusividad legítima del uso de la fuerza se refería solamente a la coacción física. Bourdieu, sin embargo, da una vuelta de tuerca interpretativa y equipara «legítima» a consentida, de modo que, según él, la legitimidad de la coerción física y simbólica equivale a aceptación de la dominación por los dominados.

El segundo hilo del que tira nuestro sociólogo es el de «campo» mediante el que pretendió comprender el espacio social como una superposición interactiva de territorios especializados, cada uno con sus reglas de juego, donde los agentes, actuando como competidores por la obtención de recursos de diferente contenido (las diversas formas de capital: desde el económi-

autor, un testimonio de una duradera colaboración: «Memoria de un pensamiento», en J. L. Moreno Pestaña y F. Vázquez García (eds.), Pierre Bourdieu y la Filosofía (Barcelona: Montesinos, 2006, pp. 23-35). Este último texto recuperado gracias a la labor muy destacable de la «escuela de Cádiz», que tempranamente, gracias su mentor Francisco Vázquez García, produjo una obra de síntesis muy estimable, Pierre Bourdieu. La sociología crítica de la razón (Barcelona: Montesinos, 2002).

${ }^{4}$ Bourdieu y Passeron, La reproducción, 45. Antes, también con J. C. Passeron, había publicado en su editorial Les Éditions de Minuit, Les héritiers. Les étudiants et la culture (hay edición española en Buenos Aires: Siglo XXI, 2003), donde se acuñaba un canon de análisis de la distribución y reproducción del capital cultural a través de las desigualdades de acceso y éxito dentro del sistema de enseñanza. Durante mucho tiempo esta clase de análisis se erigieron en marcos de referencia inevitables en las aproximaciones críticas al campo de la educación. Muchos años después, el propio autor juzgaba como injustas las acusaciones de funcionalismo ( funcionalismo de lo peor», decía irónicamente el propio Bourdieu) formuladas tempranamente contra esta obra y La reproducción al ser leídas de manera mecanicista, «fatalista»o finalista (el sistema escolar como una suerte de artefacto de reproducción automática y como una conspiración de la burguesía contra las clases dominadas). Para una reactualización de esas acusaciones, ya muy presentes en los años setenta, véase Enrique Martín Criado, La escuela sin funciones. Crítica de la sociología de la educación crítica (Barcelona: Bellaterra, 2010). Y para un comentario crítico de la crítica, véase mi reseña de este libro en Reseñas de educación // Education Review, 13 (noviembre 2010), disponible en http://w.w.w.edrev.info/reviews/revs266.pdf. Mucho antes Mariano Fernández Enguita, Marxismo y sociología de la educación (Akal: Madrid, 1983), 12-13, incidía así mismo en "una cierta coincidencia entre éstas [las teorías de la reproducción] y los anteriores análisis funcionalistas, pues, a pesar de atribuir fines diametralmente distintos a la escuela e ir acompañadas de concepciones y valoraciones diametralmente opuestas de la sociedad, ambas dibujaron una imagen de la escuela como algo todopoderoso capaz de arrasar cualquier cosa que se le pusiera por delante en el ejercicio de sus "funciones", bien fuera al servicio de la modernización social o, prosaicamente, del capital». 
co al cultural), son portadores de habitus (dispositivos infraconscientes de conducta), propios de cada campo. En estos campos o subconjuntos sociales se construye y reconstruye dinámica y conflictivamente la sociedad. ${ }^{5}$ Dos precedentes insoslayables de estos cursos hay que buscarlos precisamente en los estudios dedicados al campo de los profesores universitarios en 1984 (Homo academicus) y al campo de las escuelas de las elites rectoras del Estado francés en 1989 (Noblesse d'état). Hay quien ha visto en este último libro «un verdadero tour de force para integrar su teoría de campo dentro de los postulados básicos de la reproducción». ${ }^{6}$ Sea como fuere, como ya se mencionó, el modelo de la reproducción siempre está presente en el autor, aunque él se cuida mucho de negar que tenga algo que ver con un funcionalismo al revés, ni desde luego con determinismo económico o de otro tipo. Probablemente no siempre utilizó sus conceptos centrales (campo/habitus) con la misma intensidad y es más que evidente que el matiz no determinista y más maleable avanza conforme se despliega su obra, convirtiendo la idea de «campo» en el objeto de su preferencia investigadora. Son muchos y de naturaleza muy distinta los campo observados por Bourdieu, a menudo de naturaleza cultural. ${ }^{7}$ En el caso que comentamos ahora es el Estado, como "campo del poder», el motivo de sus charlas a los asistentes a las clases del Colegio de Francia. En ellas imagina al Estado como «metacampo» o «campo de los campos», entendiendo por tal el factor que hace factible el funcionamiento de los demás campos. El Estado sería, por consiguiente, como el «banco central de capital simbólico» (p. 173) («gran fuente y reserva de capital simbólico»), que existe en cuanto existen los campos que se disputan el monopolio de la violencia simbólica legítima. Por tanto, El Estado vive camuflado en los campos, como «poder por encima de los poderes»,

\footnotetext{
${ }^{5}$ El concepto de "campo» es antiguo en el conjunto de su obra pues su uso se remonta a los años sesenta. Véase, por ejemplo, su conferencia de 1976 titulada "Algunas propiedades de los campo»s, en P. Bourdieu, Cuestiones de sociología (Madrid: Istmo, 2000), 112-119. No obstante, se podría decir que su empleo es cada vez más sutil, relevante y estratégico en la medida que Bourdieu quiere hacer cierto, parafraseando el célebre dictumhegeliano, que lo social es lo relacional, esto es, que la dinámica de fuerzas dentro de la sociedad se puede representar a través de una teoría de los campos, entendidos como espacios de posiciones y relaciones entre los agentes intervinientes en diversas esferas de la totalidad social (económica, cultural, política, etc.).

${ }^{6}$ Martín Criado, «De la reproducción al campo escolar», 101.

7 También en Les Éditions de Minuit se publicó en 1979 la obra La distinction. Critique social du jugement, de la que existe versión española, La distinción. Criterio y bases sociales del gusto (Madrid: Taurus, 1988), una de las obras más citadas en la historia de la sociología, en la que intentó analizar la relación entre el consumo, los gustos y estilos de vida de las distintas clases sociales.
} 
como «invención menta»l y fuente de imposición de lo universal. ${ }^{8}$ A este discurso argumentativo central del Estado como realidad inventada y campo de los campos, se añade la caracterización y valoración del Estado de manera ambivalente en tanto que instancia simultáneamente integradora y dominadora. En este último terreno, la fuerte impregnación weberiana de sus posiciones acerca de las formas de dominación, se recubre y completa del manifiesto ascendente de su otro polo inspirador: E. Durkheim. De este toma la idea del Estado como organizador de la integración orgánica de los ciudadanos, apartándose como de la peste de la interpretación marxista del Estado como mero gestor de los intereses de las clases dominantes. En efecto, Bourdieu apuesta por una consideración compleja del Estado, que poseería la faz de un Jano bifronte: es un metacampo que hace posible la dominación con el consentimiento de los dominados, pero es también condición de posibilidad para la integración de los dominados merced al acceso y disfrute de los bienes y servicios de todo tipo que garantiza. En una palabra, la doble cara del Leviatán es similar a la doble cara de la escuela (segrega e integra). ${ }^{9}$

\section{MODELOS HISTÓRICOS DE CONSTRUCCIÓN DEL ESTADO: CONTRA LA AMNESIA DE LA GÉNESIS}

Los tres cursos del Colegio de Francia, con sus respectivas veintitrés clases, sirven a modo de organizador de las partes y capítulos del texto, que,

\footnotetext{
${ }^{8}$ Bourdieu, Sobre el Estado, 273. En algún momento califica al Estado de «entidad teológica, una entidad que existe a causa de su creencia» (p. 24). El estilo casi conversacional de las clases acentúa ese énfasis, un tanto exagerado y provocativo, a favor la dimensión del Estado como creencia o imaginario, aunque, como se sabe, Bourdieu siempre fue partidario de una ontología dual gracias a la cual las instituciones tendrían una doble existencia: en las cosas y en las mentes de los sujetos. En todo caso, nos parece más clara y sistemática la definición de "campo» que Bourdieu hace en otra obra suya confeccionada con su discípulo Louis Wacquant en Una invitación a la sociología reflexiva (Madrid: Siglo XXI, 2005), 169.

${ }^{9}$ El carácter complejo del Estado moderno, muy lejano del mito historiográfico del Estado como conjunto de instituciones en las que se plasma la conquista progresiva del ideal de administración de libertades al servicio de la comunidad, está muy presente en la obra del historiador portugués António Hespanha, Vísperas del Leviatán(Madrid: Taurus, 1986), que, pese a no ser utilizada por Bourdieu, resuena como un eco de fondo. El Estado lejos de ser un árbitro cada vez más justo y menos intervencionista conforme avanza el modelo liberal, es una instancia más invasiva, refinada y controladora. En efecto, como afirmaba M. Foucault, las «luces que han inventado las libertades han inventado también las disciplinas» (Vigilar y castigar. Nacimiento de la prisión, Madrid: Siglo XXI, 1984), 225. Si del orden disciplinario foucaultiano pasamos al orden de la subjetividad de las sociedades de control, nos encontramos con conceptos como "gubernamentalidad» o "poder pastoral», que, a nuestro modo de ver poseen más de una concurrencia con la «violencia simbólica» de Bourdieu, pero que este último en sus trabajos inexplicablemente ni siquiera menciona.
} 
además, se completan y benefician de unos muy jugosos anexos, dentro de los que destaca, como aportación tan valiosa como infrecuente, un índice de conceptos (junto al más habitual onomástico) que ayuda al lector, como si de un mapa se tratara, a orientarse, localizar y volver sobre determinados aspectos del rico universo de nociones que se tocan en el libro.

En realidad, la recopilación de estas clases es obra inédita y no preparada por el propio autor para su publicación, cosa que sí ocurrió con algunas de las clases que impartió durante los veinte años (1981-2001) que ocupó la cátedra de tan ilustre institución. ${ }^{10}$ Como repite él mismo en varios momentos, el comportamiento expresivo dentro del aula no puede equiparse con las convenciones que rigen la confección de un libro; en las exposiciones ante el estudiantado rige un estilo más suelto, a menudo redundante, en ocasiones desigual, a veces expresamente "didáctico», de manera de que como apuntan los propios editores, este compendio de sesiones de clase «está más cerca de la lógica del descubrimiento científico que de la exposición escrita» (p. 7). ${ }^{11}$ Por lo demás, como en toda su obra, Bourdieu recurre a figuras retóricas muy suyas, tales como el amor sin freno al retruécano, que a veces provoca un efecto deslumbrante y otras se nos antoja abusivamente repetitivo hasta la extenuación. También cabe justificar, en parte, los altibajos del texto por estar dirigido, como su autor reconoce, a un público extraordinariamente variado (desde expertos en su obra hasta no iniciados en sus misterios). ${ }^{12}$ Estamos, pues, ante una clases con las que pretende ofrecer una exégesis crítica de otros autores, principalmente historiadores y sociólogos, que se ocuparon de la historia de la institución estatal. Frente a ellos persigue mostrar y afirmar sus tesis esgrimiendo su propia batería de conceptos y las fuentes teóricas a partir de las que se ha ido nutriendo su teoría genética del Estado.

\footnotetext{
${ }^{10} \mathrm{El}$ año de la muerte de Bourdieu se publicó en España Lección sobre la lección (Barcelona: Anagrama, 2002), que había sido su lección inaugural en el Collège de France (Leçons sur la leçon, Paris: Minuit, 1982).

${ }^{11}$ Nada que ver, por ejemplo, con el armazón discursivo, cristalino, cartesiano y exacto, del curso impartido en la Sorbona en 1904-1905 por Émile Durkheim, publicado más tarde en 1939. La versión española que manejamos es Historia de la educación y de las doctrinas pedagógicas. La evolución pedagógica en Francia (Madrid: La Piqueta, 1982).

12 En efecto, la asistencia a las sesiones en el Colegio de Francia queda abierta al público, lo que rompe la unidad cognitiva del auditorio y establece lo que en algún momento Bourdieu llama un alumnado a varias velocidades.
} 
El contenido principal de este libro, por tanto, consiste en el análisis histórico de la construcción del Estado como campo de poder, tomando como base el comentario de las interpretaciones de historiadores y teóricos sociales sobre el tema. Por expresarlo de alguna manera sintética, la macrotesis que envuelve sus más de 500 páginas sostiene que la noción del Estado como «monopolio de la violencia física y simbólica legítima» solo cabe ser comprendida y explicada a través de la historia de la institución estatal. En última instancia, el estructuralismo genético consiste precisamente en reivindicar la dinámica histórica para comprender las permanencias y alteraciones de artefactos estructurales con los que se organiza y sustancia la vida social de los seres humanos. Convergen, pues, en su ambicioso empeño la mezcla de vetas sociológicas e históricas como un todo inescindible.

A tal fin, durante el primer curso (1989-1990) se ocupa de definir, siguiendo y corrigiendo a M. Weber, su idea de Estado como detentador del monopolio legítimo de la violencia (física y simbólica), y distanciándose muy expresamente de la concepción marxista a la que califica como «funcionalismo de lo peor» (un Estado diabólico siempre al servicio de las clases dominantes). Simultáneamente pasa revista a las obras de S. N. Eisendadt, P. Anderson, B. Moore, R. Bendix, T. Skocpol, etc. Ya aquí se nota el rechazo de la idea althusseriana de "aparato» (aparatos de Estado) para huir del mecanicismo reproduccionista, reclamando, como alternativa, la noción de "campo», esto es, reivindicando una visión compleja del Estado como realidad «inventada» capaz de ostentar la capacidad de producir, a través de las estrategias de lo público, lo universal. El monopolio estatal de lo universal, del conjunto de ideas reconocidas y asumidas ampliamente dentro de la sociedad, sería la base y el cemento aglutinante de la dominación, cada vez más fundada en lo racional y simbólico. ${ }^{13}$

En el segundo curso (1990-1991), prosigue su tarea de comentario de algunas relevantes aportaciones de la sociología histórica, especialmente de M. Weber, N. Elias y Ch. Tilly, Ph. Carrigan y D. Sayer. Se distancia aquí de cualquier economicismo y subraya, como así lo hacen los dos últimos auto-

\footnotetext{
${ }_{13}$ Precisamente, en otros de sus libros, Meditaciones pascalianas (Barcelona: Anagrama, 1999), 112, nuestro sociólogo considera que «los dominados tendrán que utilizar cada vez más la razón para defenderse de las formas cada vez más racionales de dominación», de modo que las ciencias sociales se erigieran en un medio de los dominados para desenmascarar y contrarrestar las estrategias de dominación y lo escandaloso de ese monopolio de lo universal, siendo así que «los fines y medios de la lucha política permanente [deberían dirigirse] a la universalización de las condiciones de acceso a lo universal».
} 
res citados, el carácter de «revolución cultural»que supuso la erección del Estado moderno. En efecto, el Estado llega a ser el principal instrumento de ordenación y construcción de la realidad social merced a la progresiva concentración de diversas especies de capital (físico, económico, cultural, y simbólico) y así devino en un «metacampo», una realidad «meta», profundamente ambigua (generaliza bienes y servicios al tiempo que los monopoliza), condición indispensable para el funcionamiento de los demás campos que ocupan el espacio social.

Finalmente, en el tercer curso (1991-1992), estudia el paso del Estado dinástico y su lógica de perpetuación familiar al Estado moderno regido por la «razón de Estado», la neutralidad burocrática y la subsiguiente «desfamiliarización» progresiva. Aquí alude a la constitución de la «nobleza de Estado», ${ }^{14}$ la armadura del Estado territorial y, siguiendo la idea de «comunidades imaginarias» de B. Anderson, la consiguiente construcción/invención del nacionalismo. La constitución del campo burocrático es la premisa de todo ello: «La concentración va acompañada de monopolización de una determinada categoría, aquellos a los que llamo nobleza de Estado» (p. 319). Al final, el campo burocrático impone al conjunto social su racionalidad universalizadora como verdad incontrovertida y «natural».

Nos encontramos sin duda, a pesar de las desigualdades de tensión intelectual existentes dentro del texto, ante una obra de madurez en la que Bourdieu desgrana y pone a prueba la multitud de recursos teóricos que han jalonado su trayectoria. Por lo tanto, al tiempo que describe y explica la génesis del Estado, recapitula sobre el poder explicativo de su instrumental heurístico. Por eso, más allá de discrepancias de fondo y de matiz con algunas de sus tesis, nos interesa destacar su valiosa vocación teórica. Ciertamente, para Bourdieu la epistemología no es un mero complemento u ornamento espiritual de la labor empírica: «se trata de conocer los instrumentos para saber el efecto que nuestros instrumentos de conocimiento producen en los objetos» (p. 131). Se trata, pues, parafraseando su pensamiento, de diseccionar la lógica específica de la génesis burocrática a fin de describir la naturaleza específica de esa lógica. De ahí que la investigación de historiadores (los M. Bloch, J. Le Goff, E. P. Thompson, E. Hobsbawm, G. Duby, E.

\footnotetext{
${ }^{14}$ Por tal se entiende los egresados de las grandes écoles francesas, conjunto de instituciones sumamente selectivas y elitistas, donde se forjan y concentran los futuros estratos dirigentes del Estado, los consejos de administración y otros espacios de poder. En la noblesse d'État se acumulan en altas dosis las diversas formas de capital (cultural, económico, político) y se fermenta el ideal de servicio público.
} 
H. Kantorowicz. E. Panofski etc.), y de otros investigadores de lo social (M. Weber, N. Elias, etc.), ${ }^{15}$ se utilice a modo de material empírico y fuentes secundarias para rastrear y comparar la edificación, principalmente en Europa y desde el siglo XII, de un campo de poder que finalmente se caracterizará por la gestión y organización del consentimiento de los dominados merced a la concentración y monopolio de recursos materiales y simbólicos. Ello, en realidad, supone que el Estado administra la «violencia simbólica», esto es, el trasfondo cultural de ideas que permite la complicidad de los dominados en su situación de dominación. Por eso decía A. Gramsci que «el Estado es hegemonía acorazada por la coerción», ${ }^{16}$ o sea, una suerte de violencia más consenso, atinada reflexión que, quizás por la obsesión de Bourdieu de dejar atrás a Marx, no encuentra mención o glosa alguna en su obra. Con mayor razón, tampoco gusta el sociólogo francés del concepto marxista de «ideología», aunque sus sucedáneos conceptuales tales como «sodicea» (estrategias argumentativas justificadoras de lo establecido) o «comprensión dóxica» (una comprensión que no conoce las condiciones sociales de su misma posibilidad) se nos antojan un tanto alambicados. En todo caso, el pensamiento de nuestro autor practica una sugerente «sociología negativa», que, a nuestro entender, conlleva una vigilancia epistemológica siempre alerta y sospechosa contra la aparente transparencia y la supuesta objetividad del mundo social. ${ }^{17}$

Por añadidura, la reflexión sobre la génesis del Estado conduce a una provechosa meditación sobre las conexiones entre historia y sociología, ${ }^{18}$ una de las recurrencias en toda su producción científica. En verdad, «la oposición sociología/historia es un invento histórico, construido históricamente, que puede ser deconstruido históricamente. La historización tiene como función liberar estas limitaciones históricas insertadas por la historia

\footnotetext{
${ }^{15}$ No siendo motivo central de mis comentarios, no debemos dejar de mencionar que el libro contiene muy certeras reflexiones sobre el uso de la comparación en ciencias sociales, especialmente oportunas cuando se refieren a las contribuciones de historiadores y sociólogos sobre las particulares vías de acceso al Estado moderno, pensamientos que evocan la amplia acogida que hace años tuvo el debate acerca de las transiciones del feudalismo al capitalismo y las modalidades de revolución burguesa.

${ }^{16}$ Dominique Grisoni y Robert Maggori, Leer a Gramsci (Madrid: ZERO, 1974), 130.

17 De Gaston Bachelard toma la idea de «vigilancia epistemológica». Quizás los «maestros de la sospecha», Marx, Nietzsche y Freud, podrían ratificar esta sentencia suya: «cuanto más comprendo, más desconfío; cuanto más sencillo parece, más complicado debe ser» (p. 160). Por cierto, sus relaciones con ellos tres son muy inestables e irregulares, cuando no incomprensiblemente desaprovechadas, como más adelante se verá respecto a la genealogía nietzscheana.
}

${ }_{18}$ Bourdieu, Sobre el Estado, 125-131. 
en los inconscientes» (p. 127). Justamente esa labor de historización permite desmontar los supuestos implícitos del código disciplinar de cada territorio académico. Por lo que hace a la historiografía, se caracteriza, según él, por practicar una filosofía implícita de la historia (aceptar que lo que ocurrió tenía que ocurrir) y un notable ateoricismo: «Los historiadores están muy irritados con la teorización, con cualquier tipo de teorización, en la medida que, muy a menudo, las vocaciones de historiador pagan una cuota de inscripción que consiste en renunciar a la ambición de generalización, que se deja, con cierto desprecio - ambivalente—, a los sociólogos» (p. 131). Esta aseveración, nada infrecuente en nuestro autor, cuenta además con una larga tradición en el país vecino, donde la lucha por la hegemonía entre las nuevas ciencias sociales y la historia se expresa reiteradamente desde los tiempos de la III República. ${ }^{19}$

Otro aspecto teórico y metodológico muy pertinente y destacable de la obra que comentamos son las concomitancias, no explícitas pero bien visibles para nosotros, entre el estructuralismo genético que nuestro sociólogo confiesa practicar y la genealogía foucaultiana que pretende ignorar. El propio autor niega que su aproximación tenga algo que ver con la mirada genealógica.

En otras palabras, uno de los efectos del poder simbólico asociado con la institución del Estado es precisamente la naturalización, en forma de doxa, de suposiciones más o menos arbitrarias que estuvieron en el origen mismo del Estado. Además, solo la investigación genética puede recordarnos que el Estado, y todo lo que sigue, es una invención histórica, un artefacto histórico, y que nosotros mismos somos invenciones del Estado. Hacer una historia genética del Estado, y no una genealogía en el sentido de Foucault, es el único antídoto real para lo que yo llamo la amnesia de la génesis, que es inherente a cualquier institucionalización del éxito, cualquier institución que logre imponerse implicando el olvido de su génesis. ${ }^{20}$

Pero la «amnesia de la génesis», feliz denominación, y la deseternización de las verdades tenidas por verdaderas es precisamente la tarea consus-

\footnotetext{
${ }^{19}$ En 1908 la controversia entre E. Durkheim y Ch. Seignobos se puede ver en «Débat sur l'explication en histoire et en sociologíe», Bulletin de la societéfrançaise de philosophie, 8 (1908): 217-247.

${ }^{20}$ Bourdieu, Sobre el Estado, 162-163.
} 
tancial al genealogista. No entendemos cómo Bourdieu, de cuya erudición poca duda cabe y que no deja a veces de citar con complacencia a Nietzsche, pueda desconocer la labor deseternizadora y transvalorativa de todos los valores realizada por el filósofo alemán en libros como La genealogía de la moral o Aurora. Tampoco acabamos de comprender cómo despacha con cajas destempladas a la genealogía foucaultiana sin referirse al texto central de la misma, o sea, a uno de los ensayos más celebrados de M. Foucault, que lleva por título Nietzsche, la génealogie y l'histoire. ${ }^{21}$ Allí se afirma algo que, a buen seguro, podría suscribir el estructuralismo genético de Bourdieu, a saber, «que detrás de las cosas hay otra cosa bien distinta: no un secreto esencial y sin fecha, sino el secreto de que no tienen esencia».22 Efectivamente el paso a contrapelo del cepillo de la historia sobre los problemas que nos afectan en el presente evita la «amnesia de la génesis», porque, en verdad, lo peor del olvido es el olvido de que hemos olvidado. ${ }^{23}$

${ }^{21}$ Escrito en 1971 en homenaje a Jean Hyppolite, existen varias versiones en castellano (La Piqueta, Madrid: 1992, o Pre-Textos: Valencia, 1988 y 2004). Allí se realiza una lectura sumamente creativa a partir de algunos textos-clave del pensador alemán. Desde entonces, esta lectura funda de manera expresa una interpretación en clave genealógica del inmenso y controvertido legado nietzscheano. En el fondo, la genealogía persigue y fomenta una búsqueda del origen como surgencia y emergencia de las cosas dichas sobre el mundo, una áspera mirada de las prácticas sociales y discursivas que se hace desde el presente. De ahí que el propio Foucault hablara de una «historia del presente», problematizadora del hoy mediante la inmersión crítica en la historia, pasando «a cuchillo», parafraseando a Nietzsche, el pasado. Por otra parte, las relaciones entre Bourdieu y Foucault tuvieron, dentro de una admiración mutua, las aristas propias de dos pensadores superlativos y competidores dentro del campo intelectual francés. En un breve pero intenso y brillante texto de Bourdieu sobre la herencia de Foucault ( ¿¿Qué es hacer hablar a un autor? A propósito de Michel Foucault», en Capital cultural, escuela y espacio social (México: Siglo XXI, 2005), 11-20, nos recuerda cómo a menudo lo que queda de un gran autor es un conocimiento ex auditu, un rumor intelectual del que se recuerda, verbigracia Foucault, más la moda de poner títulos en infinitivo que emplear sus contribuciones más importantes.

Por supuesto, existe ya una notable nómina de autores que se ocupan del modelo de análisis genealógico en España y en otros países de lengua española. Por nuestra parte, resumimos nuestra posición en Raimundo Cuesta, Juan Mainer y Julio. Mateos, «La genealogía, historia del presente y didáctica crítica», en J. Mainer (ed.), Pensar críticamente la educación escolar (Zaragoza: Prensas Universitarias de Zaragoza, 2008), 51-82. Para consultar una invitación a practicar la genealogía hecha por el sociólogo francés R. Castel a sus colegas, véase «Michel Foucault y la historia del presente», Con-Ciencia Social, 17 (2013): 93-99.

${ }^{22}$ M. Foucault, Nietzsche, la genealogía y la historia (Valencia, Pre-textos, 2004), 18-19.

${ }^{23}$ Esta es la base de la naturalización y cosificación de la realidad presente. Bourdieu lo expresa muy bien cuando dice: «Una institución que triunfa se olvida y hace que olvidemos que tuvo un nacimiento, que tuvo un comienzo» (p. 163). 


\section{UN LEGADO TEÓRICO VIVO Y AMBICIOSO QUE EXIGE UN USO MODESTO}

No merece, ciertamente, el olvido la ambiciosa obra de Bourdieu y se agradece todavía la tarea de quienes, cual albaceas de su legado, editan los abundantes flecos que, como el libro objeto de nuestro comentario, todavía no habían visto la letra impresa. Por otro lado, resulta difícil, al margen de ciertas ortodoxias y algunas modas recientes, ${ }^{24}$ no apreciar en su ingente obra la mano de un pensador de gran talla. Aunque su presunta mirada desde las alturas ha provocado que uno de sus discípulos y antiguos colaboradores, Luc Boltanski, califique su enfoque de «sociología cenital de la dominación», porque, a su entender, sobrevolaría la realidad y mantendría una excesiva y altiva distancia respecto a las posibilidades de los agentes sociales que aparecerían como «incautos culturales», como sujetos engañados incapaces de ver lo que divisa el sociólogo crítico desde las cumbres de sus artefactos teóricos. ${ }^{25}$ Sin duda este tipo de objeciones se inscriben en la lógica de producción de la verdad postestructuralista, pero no conviene ignorar que el propio Bourdieu estuvo muy atento y no permaneció insensible a los diversos «giros» lingüísticos y culturales que invadieron y enriquecieron las ciencias sociales en las últimas décadas. Su mismo énfasis en la dimensión simbólica de la vida social y en la aceptación del carácter performativo de los lenguajes y representaciones sociales es prueba irrefutable de lo que afirmamos. Otra cosa es que nuestro autor jamás renunciara a un concepto de ciencia ajeno al habitual relativismo del pensamiento postmoderno, y que se negara a desvincular las prácticas del espacio social de estructuras profundas e inconscientes. Las estructuras objetivas y las estructuras mentales

\footnotetext{
${ }^{24}$ En el campo de la sociología, como en todos los espacios académicos, rige la ceremonia de asesinar al padre. Ritual en el que suelen desempeñar papel de prima dona algunos pretendientes a la sucesión. Por otra parte, aunque Bourdieu fue tachado en vida de marxista y antimarxista al mismo tiempo, su afán por separarse de ciertas versiones de tal escuela hizo que su distancia de Marx se interpretara en diversas claves políticas. Su gusto por la paradoja, como se puede apreciar en la cita que sigue, no contribuyó a mejorar las cosas: "A menudo repito que el marxismo es "insuperable" [Sartre había dicho que el marxismo era el horizonte filosófico insuperable de nuestra época], pero a condición de superarlo» (p. 370). También parece obvio que en más de una ocasión (resulta paradigmática alguna de las obras de T. Judt o, entre nosotros, de F. Fernández Buey), se mete en la misma bolsa y se echa a la basura toda la tradición intelectual crítica francesa de la época de Bourdieu bajo la acusación, a menudo poco justa, de frivolidad y banalidad.

${ }^{25}$ Luc Boltanski, De la crítica. Compendio de sociología de la emancipación (Madrid: Akal, 2014). Como alternativa, propone Boltanski una «sociología pragmática de la crítica», cuya diferencia principal con la sociología crítica tradicional estribaría en abandonar la óptica cenital y volver a mirar la realidad a partir de la acción y percepción de los agentes sociales.
} 
constituyen, con diversos énfasis según los casos estudiados, el haz estructuralista y el envés constructivista de su método de investigación social. ${ }^{26}$

Más allá de una innecesaria defensa o impugnación a la totalidad de una obra tan polifacética, nos parece oportuno indicar que, con vistas a lo que a nosotros nos interesa, el peligro de Bourdieu reside en la omnipotencia teórica que impregna su quehacer intelectual, aunque él mismo gustaba decir que «la teoría, porque es como el aire que se respira, está por doquier y en ningún sitio». ${ }^{27}$ Pero, en realidad, la fábrica Bourdieu se convirtió en una manufactura de un complejo artefacto teórico compuesto de un enjambre de conceptos, fruto de su enorme capacidad imaginativa para inventar nombres y hacerlos girar en el carrusel de una magna representación del espacio social. A sus incondicionales, y los que viven de ello, les queda la ardua e imposible tarea de descubrir al «verdadero» Bourdieu.

A nosotros, nos toca, desde nuestra propia circunstancia profesional y vital, una labor más limitada y muy distinta: hacer un uso modesto de una teoría ambiciosa donde las haya. En efecto, como personas vinculadas al mundo de la educación (de la docencia y la investigación) siempre concebimos el bagaje teórico como una apropiación creativa de ideas ajenas (una suerte de robo sin carga penal), sin veneraciones ni dogmatismos de ninguna clase y al servicio de un interés crítico-emancipador. De ahí que nuestro empleo de Bourdieu, como el de otros autores, en la investigación educativa haya sido voluntariamente oportunista, ocasional y pragmático, sin adhesión irrestricta de ningún género a un surco teórico del que compartimos algunos extremos y rechazamos otros. ${ }^{28}$

Compartimos principalmente tres asuntos de extraordinaria relevancia para la práctica de la investigación educativa: su consideración general de la

\footnotetext{
${ }^{26}$ Así lo expresa muy rotundamente en el prólogo («Estructuras sociales y estructuras mentales») de su libro La nobleza de Estado. Educación de elite y espíritu de cuerpo (Buenos Aires: Siglo XXI, 2013), 13-20. Allí mismo dice que: «Es bueno recordar, contra cierta visión mecanicista de la acción, que los agentes sociales, individual y también colectivamente, construyen la realidad social, y es necesario no olvidar, como suelen hacer los interaccionistas simbólicos y los etnometodólogos, que ellos no construyen las categorías que hacen funcionar en esa construcción: las estructuras subjetivas del inconsciente que operan en los actos de construcción, de los cuales las apreciaciones escolares son un ejemplo entre otros, resultan de un largo y lento proceso inconsciente de incorporación de estructuras objetivas» (p. 50).

${ }^{27}$ Las reglas del arte. Génesis y estructura del campo literario (Barcelona: Anagrama, 1995), 266.

${ }^{28}$ Recientemente en nuestro trabajo sobre M. Foucault, «Las una y mil inquietudes de la obra de Foucault», Con-Ciencia Social, 17 (2013): 79-92, hemos insistido en que la recepción de un autor y una obra no equivale a un rígido lo tomas o lo dejas.
} 
institución escolar, sus conceptos de campo y habitus y la idea de las disciplinas escolares como «arbitrarios culturales» construidos históricamente. En cuanto al primero, se trata de esa visión crítica y ambivalente de la escuela que tanto rechazo produce entre el profesorado y entre aquellos que vieron o tuvieron en la escuela una vía de ascenso social, porque, al decir de Bourdieu «la escuela es, en efecto, un instrumento de integración, pero de la integración que permite la sumisión» (p. 313) ${ }^{29}$ En segundo lugar, sus nociones de «campo» $\mathrm{y}$ «habitus» poseen una enorme potencialidad heurística en la investigación educativa. Desde luego, como defiende la ya citada aportación de E. Martín Criado, ${ }^{30}$ sobre todo si amortiguamos la tentación mecanicista que proyecta la imagen de «sistema» o "aparato» y la sustituimos o alternamos con la de "campo», ${ }^{31}$ a la hora de estudiar las vías que han existido en la forja de las instituciones nacionales de educación en los distintos países, un tema estratégico de la historia de la educación. ${ }^{32}$ También, no obstante, la noción de «campo», en tanto que red de fuerzas, es más que oportuna y fructífera para escudriñar la sociogénesis de los cuerpos docentes. A tal fin, la imagen de un «campo profesional» puede y debe ser combi-

\footnotetext{
${ }^{29}$ Transité por esta mirada acerba de la institución escolar en Felices y escolarizados. Crítica de la escuela en la era del capitalismo (Barcelona: Octaedro, 2005). Las reacciones que ocasionó, salvando las distancias, me recordaron las mismas sensaciones que describe Bourdieu a propósito de La reproducción, en una entrevista sobre educación que le hicieron en Tokio en 1989, donde indica que «ese libro era difícilmente soportable... era un libro que hacía daño» (Capital cultural, escuela y espacio social, p. 158). Y es así porque se pone en solfa una creencia muy asentada sobre el valor positivo de la escolarización, fruto hoy de un verdadero consenso transcultural y global.
}

${ }^{30}$ Martín Criado, «De la reproducción al campo escolar».

${ }^{31}$ Aunque no estimamos pertinente estigmatizar la idea de «sistema», porque bajo él se puede albergar tanto una visión mecanicista como otra de signo opuesto. Por sistema no debe entenderse un circuito cerrado o un carrusel que gira cual rueda sin parar reproduciendo la vida social, sino un conjunto de relaciones sometidas históricamente a pulsiones y efectos de continuidad y cambio.

${ }^{32}$ Hay que mencionar la visión no determinista de este asunto en M. Archer, Social Origins of Educational Systems (London: Sage, 1979). En España el canon de la formación del sistema educativo sigue bajo el signo del politicismo y el paradigma del fracaso, sembrado por la obra del profesor M. de Puelles que, por ejemplo, puede consultarse en su Estado y educación en la España liberal (1809-1857). Un sistema educativo nacional frustrado (Barcelona: Pomares, 2004). La aplicación y uso intensivo del «campo educativo» está por hacer. Eso no quita aportaciones que han aplicado modelos muy interesantes, como se muestra en la obra de A. Viñao, Sistemas educativos, culturas escolares y reformas (Madrid: Morata, 2002), y en Escuela para todos. Educación y modernidad en la España del siglo XX (Madrid: Pons, 2004), que sigue la línea abierta y transitada merced al uso de conceptos clave para examinar los sistemas educativos («sistematización», "segmentación», "progresividad», etc.), tomados de la obra de Frank Ringer y Brian Simon, El desarrollo del sistema educativo moderno. Cambio estructural y reproducción social (Madrid: Ministerio de Trabajo, 1992). Por nuestra parte, empleamos el concepto «modo de educación» para explicar el desenvolvimiento histórico del sistema educativo español. Véase R. Cuesta, J. Mainer y J. Mateos, «Reformas y modos de educación en España: entre la tradición liberal y la tecnocracia», Revista de Andorra, 11 (2011): 18-94. 
nada con la de «habitus», el repertorio de dispositivos y prácticas sociales y pedagógicas históricamente inscritosen las entretelas de las corporaciones de profesores. ${ }^{33}$ Por último, la historia de las disciplinas escolares se puede beneficiar de las concepciones de Bourdieu sobre la construcción social del conocimiento y el papel del Estado en la legitimación del curriculum en la medida que consagra y es expresión de un orden disciplinar construido históricamente y naturalizado como eterno y necesario. ${ }^{34}$ Como ejemplo del Estado hacedor de consensos universales sobre las asignaturas, acude a la ortografía para mostrar el carácter de «invención» dentro de las fluidas guerras simbólicas por la definición de la cultura legítima. ${ }^{35}$

En fin, la obra que hemos glosado y comentado, aunque ceñida a la institución estatal, recapitula sobre muchas dimensiones del multifacético pensador galo. Su vivo y actual interés demuestra que, más allá de fidelidades perrunas o modas hipercríticas, el conjunto de la cosecha intelectual de Bourdieu no acaba de agostarse ni para el sostenimiento de una teoría social crítica en general, ni para fundamentar y enriquecer la investigación de la historia de la educación. Como decíamos en el número 6 de la revista Con-Ciencia Social en una nota escrita con motivo de su muerte en 2002, "algunos seguiremos fumando», pese a que alguien pensaba por entonces que, como el tabaco, Bourdieu hacía daño a la salud. Más de doce años después, aunque sea mejor dejar de fumar, es muy recomendable tener pronta y a mano su obra como antídoto contra las muchas patologías sociales que consumen nuestras vidas.

\author{
Raimundo Cuesta \\ Fedicaria-Salamanca \\ raicuesta2@gmail.com
}

\footnotetext{
${ }^{33}$ Asunto que parcialmente hemos tratado recientemente, con la colaboración de J. Mainer, en «Guardianes de la tradición y esclavos de la rutina: historia del campo profesional de los catedráticos de Instituto», Historia y Memoria de la Educación, 1 (2015): 351-393.

${ }^{34}$ Ese orden se expresa en el código disciplinar de las materias de enseñanza. Ensayamos un marco explicativo de este tipo, que algo debía a Bourdieu, en nuestro libro Sociogénesis de una disciplina escolar: la historia (Barcelona: Pomares, 1997).

${ }^{35}$ Sorprendentemente no cita a André Chervel, el ya clásico estudioso de la gramática y ortografía francesas, y, en general, punto de referencia inexcusable en la investigación de la cultura escolar y de las disciplinas. Véase su obra pionera Histoire de la grammair escolaire (Paris: Payot, 1977).
} 
